\title{
Challenges of Smart Business Process Management: An Introduction to the Special Issue
}

\author{
Jan Mendling ${ }^{\mathrm{a}, *}$, Bart Baesens ${ }^{\mathrm{b}, *}$, Abraham Bernstein ${ }^{\mathrm{c}, *}$, Michael \\ Fellmann ${ }^{\mathrm{d}, *}$ \\ ${ }^{a}$ Wirtschaftsuniversität Wien, Welthandelsplatz 1, 1020 Vienna, Austria \\ ${ }^{b}$ KU Leuven, Leuven, Belgium \\ ${ }^{c}$ University of Zurich, Switzerland \\ ${ }^{d}$ University of Rostock, Germany
}

\begin{abstract}
This paper describes the foundations of smart business process management and serves as an editorial to the corresponding special issue.

Keywords: Business Process Management, Smart Technologies

1. Introduction

Today's business world is complex and characterized by an extensive divi3 sion of labor. Products and services are designed and delivered with various 4 actors being involved within the providing organization and beyond. In or5 der to deliver products and services in an efficient and effective manner, it 6 is of utmost importance that the coordination between the different actors 7 inside and outside the providing organization runs smoothly. A first step tos wards a smooth operation is achieving transparency of the business process 9 that results in product and service delivery, and this transparency can be - achieved by documenting the business process including the various actors 1 involved, the activities they perform, the events and decisions that influence 2 the progress, and the information that is produced and consumed $[1,2]$.
\end{abstract}

\footnotetext{
*Corresponding Author

Email addresses: jan.mendling@wu.ac.at (Jan Mendling), bart.baesens@kuleuve.be (Bart Baesens), bernstein@ifi.uzh.ch (Abraham Bernstein), michael.fellmann@uni-rostock.de (Michael Fellmann)
} 
Division of labor in business processes calls for coordination support by the help of information systems. The specific class of information systems that explicitly support business processes is often referred to as process-aware information systems [3]. Office automation systems [4, 5], workflow management systems [6, 7], and recent business process management systems [1, 2] all support process execution based on a specification of the process as a formal business process model.

Business process management is concerned with all management activities around business processes. In the past, activities in relation to business process management have been conducted by process analysts, process managers and process engineers in a labor-intense fashion with hardly any automatic support except for generating the system configuration from the executable process model. This has been changing in recent years. Various smart techniques have been developed to automate or provide more intelligent support for process stakeholders in various stages of business process management. This special issue provides ten excellent examples of these recent developments towards smart business process management. This editorial presents them in an overarching framework and connects them with the broader spectrum of recent contributions on smart business process management.

\section{Business Process Management}

In this section, we distinguish three different levels of business process management. Figure 1 shows these three levels and their connections. The top level is often referred to as multi process management. It is concerned with the identification of the major processes of an organization and the regular evaluation of the priorities assigned to these processes. These activities interrelate with questions of strategic management and the overall process organization. The products of multi process management are often stored in a central process repository. The conceptual structure of this repository is also referred to as the process architecture.

The middle level is concerned with the management of a single process and its specification as a process model. The management activities on this level are often referred to as the BPM lifecycle [1]. This lifecycle is started once a process is selected for redesign. First, this process is documented in the discovery phase resulting in an as-is process model. Second, the process is analyzed using qualitative and quantitative analysis techniques. In this way, weaknesses and issues can be uncovered. Third, different directions 


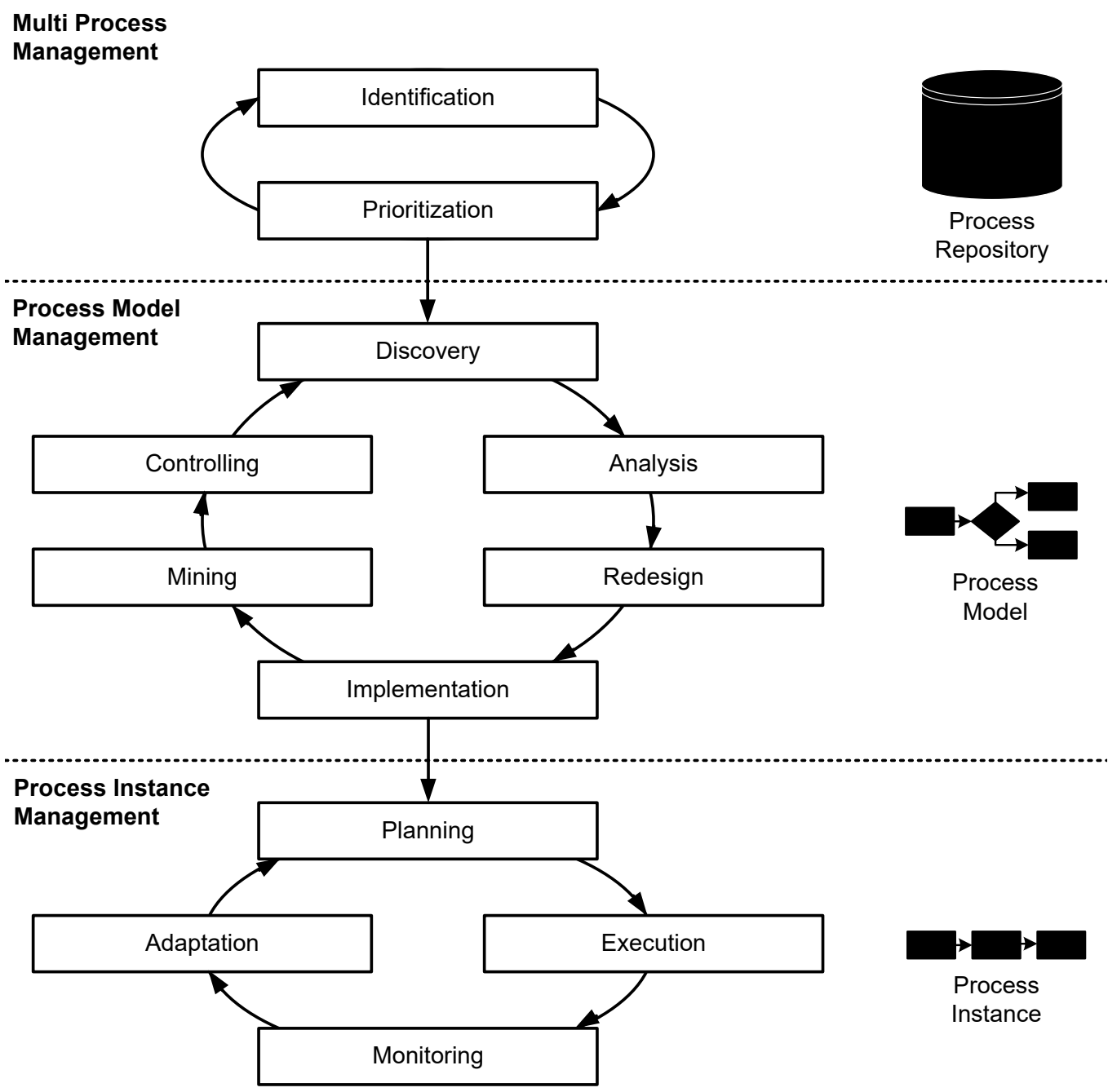

Figure 1: Three Levels of Business Process Management 
for redesign are investigated in other to fix the issues and generally improve the performance of the process. This yields a to-be process model as a specification of how the process is meant to operate in the future. Fourth, this to-be process model is taken into implementation. The corresponding information systems are designed or reconfigured and staff is trained to work according to the new setup. Fifth, and once the process has been executed for a period of time according to the new design, process mining can be used to extract knowledge about how the process operates. Sixth, process controlling is concerned with checking to which degree performance and conformance objectives are met.

The focus of the bottom level is the management of singular process instances. Instances can be planned regarding when their activities are scheduled and which resources should be involved. With or without such a schedule, process activities are executed according to the rules defined in the process model. Process monitoring continuously checks rules such as quality-of-service assertions and trigger alerts if undesired behavior is observed. Such alerts might be the reason for adapting the course of execution for an individual process instance.

Research into process mining [8] has resulted in various automatic analysis techniques that support different activities of business process management. We refer to them as smart business process management.

\section{Smart Business Process Management}

The Oxford dictionary provides three connotations for smart as (i) being clean and tidy, (ii) showing quick-witted intelligence and (iii) being quick ${ }^{1}$. All these meanings together have become a prominent attribute of information technology and analysis techniques in various application domains referred to as smart home, smart health, smart city, smart energy or smart mobility. What is in common to these smart technologies is that they integrate sensors, actuators, connectivity and analytics [9]. What they facilitate is preemptive action and coordination which is grounded in evidence, history data, state information and intelligent algorithms [10]. Since business process management is exactly concerned with coordinated action, there have been attempts to generalize the commonalities of these smart application scenarios

\footnotetext{
${ }^{1}$ https://en.oxforddictionaries.com/definition/smart
} 
in terms of their dynamic adaptation and continuous learning towards smart business process management $[11,12]$.

This section provides an overview of various techniques that are related to smart business process management. We also clarify how the contributions of this special issue relate to the overall spectrum of research in this area. Next, we explicate the notion of smartness in the context of information systems research. Then, we illustrate the richness of smart business process management by highlighting important contributions for each of the three levels.

\subsection{Smart Multi Process Management}

Prior research on smart multi process management has mainly focused on supporting repository management. This stream of research was triggered by work on similarity [13] and automatic matching techniques between business process models [14]. These provided the foundation for various automatic refactoring techniques [15] including harmonization of terminology [16], automatic service derivation [17], semantic search [18] or operations of merging business process models [19].

This special issue extends this stream of research with novel contributions on process model matching. Both Meilicke et al [20] and Klinkmüller and Weber [21] contribute to the effectiveness of automatic techniques for process model matching. The latter, Klinkmüller and Weber, contribute to the effectiveness of automatic techniques for process model matching. They investigate the importance of control flow information for the matching problem and combine a novel order relationship score with a bag-of-words approach in their self-configuring OPBOT matcher. The evaluation with standard datasets demonstrates the benefits of OPBOT.

Meilicke et al [20] build on the availability of various matchers from prior research. They introduce a voting technique that integrates process model constraints in a Markov Logic based optimization. Their evaluation demonstrates performance improvements over prior techniques.

This special issue introduces novel directions for smart multi process management. Polyvyanyy et al [22] present an overall framework for process querying. It describes generic components of a querying architecture and corresponding querying methods. Various concepts and methods are aligned with this architecture using a systematic literature review.

Kratsch et al [23] emphasize that various strategies have been proposed for prioritization of processes, but none does appropriately take dependencies 
between them into account. Their prioritization approach takes inspiration from Google's page rank algorithm and is called D2P2. D2P2 is implemented as a software prototype and evaluated using event logs data from the BPI Challenge.

\subsection{Smart Process Model Management}

There is a rich repertoire of prior research on smart process model management. Several challenges and solutions are listed in survey articles including $[24,25,26]$. Various techniques have been proposed to directly support the process of process modeling during the discovery phase, [27] is a recent example. Pattern recognition is used during the analysis phase to detect potential weaknesses [28]. The redesign phase is often supported by heuristics such as the ones summarized in [29]. Also recent technologies like crowdsourcing [30] bear the potential to be used here. The implementation phase is classically supported by workflow management technology [6]. Recent extensions provide smart support for automatic service composition [31] and process configuration [32]. Smart knowledge extraction from process-related data is often referred to as process mining. Contributions on process mining help to automatically discover models from data, check the conformance between model and execution, and derive information on decision probabilities and execution durations [8]. Such information partially informs the controlling phase, in which the process is evaluated relative to its performance and conformance objectives [33].

This special issue complements these diverse streams of research in the following ways. Claes et al [34] investigate strategies that help to model business processes in an efficient and effective way. Their Structured Process Modeling Method (SPMM) is supported by an automated modeling strategy selection and a training instrument. The benefits of the method is demonstrated in a controlled experiment with 149 master students.

The work of Suriadi et al [35] focuses on resource behavior in business processes. They develop a mining technique that provides insights into the way how resources prioritize their work. The technique is evaluated using synthetic and real-world event logs.

Wynn et al [36] address the problem of visualizing performance information of business processes in an effective way. They propose a visualisation framework called ProcessProler3D for supporting the comparison of process performance based on event logs. Their implementation is validated in a user study with industry partners. 
vanden Broucke and De Weerdt [37] develop a robust and flexible heuristic process discovery technique called Fodina. Key features of this technique are good performance in terms of process model quality and the ability to mine duplicate tasks. Fodina is tested on various event logs showing good performance in terms of F-measure.

Martin et al [38] are concerned with the identification of batch behaviour in business processes. They introduce a batch organisation of a work identification algorithm called BOWI, which provides insights into batch processing by the help of work metrics. The algorithm is evaluated with synthetic and real-world event logs.

\subsection{Smart Process Instance Management}

Prior research investigates different management aspects of process instances. The planning phase is considered in different works on scheduling [39, 40], elasticity [41], and semantic technologies [42]. Process execution is typically implemented using state and transition concepts such as provided by Petri nets. Recent research investigates the representation of these concepts by the help of blockchain distributed ledger technologies [43]. Monitoring is an important concern in order to secure that performance and conformance stays within expected ranges. Work on AB-BPM [44] is inspired by AB-testing and combines it with process automation in a self-regulatory way. Adaptation is an important mechanism for handling unforeseen situations. Various works describe approaches to help achieving flexibility at runtime [45].

This special issue extends this stream of research with an approach that helps to predict the behavior of a process instance, which can inform process planning and execution. Evermann et al [46] define their prediction approach based on neural networks. The approach is implemented and evaluated using the BPI 2012 data sets. The results illustrate the impact of various types of information on the prediction performance and the overall viability of the approach.

\section{Future Research on Smart Business Process Management}

The research reported in this special issue provides a solid foundation for future research into smart business process management. This research will have to address challenges within the three levels of business process management and across them. 
There is potential for future research within levels. On the level of the process repository, it is striking to note that research on the integration of repositories with external knowledge resources has come to a pause. Around the year 2000, the MIT Process Handbook [47] provided a promising starting point for helping organizations to discover process innovation opportunities. Mendling et al [26] describe specific challenges in this area including the discovery of ontologies from repositories and the categorization of models.

On the level of singular models, there are various opportunities to integrate existing analysis and redesign techniques with information generated from sensory data. For instance, the potential of process innovation in the retail sector based on RFID technology is highlighted in [48] as much as in the logistic sector based on AIS transponder data in [49]. Social media has been often discussed with a focus on product innovation, but there is also the potential to more intensively leverage it for process innovation, too, e.g. in the public sector [50].

There are also various opportunities for managing process instances in a smarter way using available sensor data. Indeed, many smart initiatives such as smart home, smart health, smart city, smart energy or smart mobility have an inherent behavioral perspective, which has affinity with coordination challenges of business process management. Clearly, smart technologies bear the potential for novel ways of planning, executing, monitoring and adapting process instances based on the integration of sensors, actuators, connectivity and analytics.

Finally, there is also the potential to intensify research that spans across the different levels. Most of the research across levels is currently focused on (i) moving from implementation to execution and (ii) from execution to mining and controlling. What is scarce is research that builds a bridge between the process repository and process instances. Questions in this context might relate to the consistency between the multi process perspective and the process instance perspective: in how far does the abstract description of the process landscape align with what is actually done on the transactional level? Furthermore, novel techniques that generate abstract views on an organization from a process perspective based on instance data could be highly informative to top management, in particular if it provided performance insights.

New information technology keeps on emerging and new concepts and algorithms are developed to work with process-related data. These will shape the way how business processes are managed in the future in a smarter way 
as we know it today.

\section{Acknowledgements}

We thank the authors of the papers collected in this special issue and the editor-in-chief James Marsden for comments on this editorial.

\section{References}

[1] M. Dumas, M. La Rosa, J. Mendling, H. A. Reijers, Fundamentals of Business Process Management, Springer Berlin Heidelberg, Berlin, Heidelberg, 2013.

[2] M. Weske, Business Process Management, Springer, 2012.

[3] M. Dumas, W. M. P. van der Aalst, A. H. M. ter Hofstede, ProcessAware Information Systems: Bridging People and Software Through Process Technology, Wiley, 2005.

[4] M. D. Zisman, Office automation: Revolution or evolution? (1978).

[5] R. A. Hirschheim, Office automation: a social and organizational perspective, John Wiley \& Sons, Inc., 1986.

[6] D. Georgakopoulos, M. Hornick, A. Sheth, An overview of workflow management: From process modeling to workflow automation infrastructure, Distributed and parallel Databases 3 (1995) 119-153.

[7] F. Leymann, D. Roller, Production workflow - concepts and techniques, Prentice Hall, 2000.

[8] W. M. P. van der Aalst, Process Mining - Data Science in Action, Second Edition, Springer, 2016.

[9] L. Püschel, M. Roeglinger, H. Schlott, What's in a smart thing? development of a multi-layer taxonomy, in: P. Ågerfalk, N. Levina, S. S. Kien (Eds.), Proceedings of the International Conference on Information Systems - Digital Innovation at the Crossroads, ICIS 2016, Dublin, Ireland, December 11-14, 2016, Association for Information Systems, 2016. 
[10] G. Allmendinger, R. Lombreglia, Four strategies for the age of smart services, Harvard business review 83 (2005) 131.

[11] C. Costello, O. Molloy, Orchestrating supply chain interactions using emerging process description languages and business rules, in: Proceedings of the 6th international conference on Electronic commerce, ACM, pp. $21-30$.

[12] K. B. C. Saxena, Business process management in a smart business network environment, in: The Network Experience, Springer, 2009, pp. 69-81.

[13] R. M. Dijkman, M. Dumas, B. F. van Dongen, R. Käärik, J. Mendling, Similarity of business process models: Metrics and evaluation, Inf. Syst. 36 (2011) 498-516.

[14] M. Weidlich, R. M. Dijkman, J. Mendling, The icop framework: Identification of correspondences between process models, in: B. Pernici (Ed.), Advanced Information Systems Engineering, 22nd International Conference, CAiSE 2010, Hammamet, Tunisia, June 7-9, 2010. Proceedings, volume 6051 of Lecture Notes in Computer Science, Springer, 2010, pp. 483-498.

[15] B. Weber, M. Reichert, J. Mendling, H. A. Reijers, Refactoring large process model repositories, Computers in Industry 62 (2011) 467-486.

[16] F. Pittke, H. Leopold, J. Mendling, Automatic detection and resolution of lexical ambiguity in process models, IEEE Trans. Software Eng. 41 (2015) 526-544.

[17] H. Leopold, F. Pittke, J. Mendling, Automatic service derivation from business process model repositories via semantic technology, Journal of Systems and Software 108 (2015) 134-147.

[18] O. Thomas, M. Fellmann, Semantic process modeling - design and implementation of an ontology-based representation of business processes, Business \& Information Systems Engineering 1 (2009) 438-451.

[19] M. L. Rosa, M. Dumas, R. Uba, R. M. Dijkman, Business process model merging: An approach to business process consolidation, ACM Trans. Softw. Eng. Methodol. 22 (2013) 11:1-11:42. 
[20] C. Meilicke, H. Leopold, E. Kuss, H. Stuckenschmidt, H. A. Reijers, Overcoming individual process model matcher weaknesses using ensemble matching, Decision Support Systems (2017).

[21] C. Klinkmüller, I. Weber, Analyzing control flow information to improve the effectiveness of process model matching techniques, Decision Support Systems (2017).

[22] A. Polyvyanyy, C. Ouyang, A. Barros, W. M. van der Aalst, Process querying: Enabling business intelligence through query-based process analytics, Decision Support Systems (2017).

[23] W. Kratsch, J. Manderscheid, D. Reißner, M. Röglinger, Data-driven process prioritization in process networks, Decision Support Systems (2017).

[24] M. L. Rosa, P. Wohed, J. Mendling, A. H. M. ter Hofstede, H. A. Reijers, W. M. P. van der Aalst, Managing process model complexity via abstract syntax modifications, IEEE Trans. Industrial Informatics 7 (2011) 614629 .

[25] M. L. Rosa, A. H. M. ter Hofstede, P. Wohed, H. A. Reijers, J. Mendling, W. M. P. van der Aalst, Managing process model complexity via concrete syntax modifications, IEEE Trans. Industrial Informatics 7 (2011) $255-265$.

[26] J. Mendling, H. Leopold, F. Pittke, 25 challenges of semantic process modeling, International Journal of Information Systems and Software Engineering for Big Companies (IJISEBC) 1 (2015) 78-94.

[27] A. Koschmider, H. A. Reijers, Improving the process of process modelling by the use of domain process patterns, Enterprise IS 9 (2015) $29-57$.

[28] P. Bergener, P. Delfmann, B. Weiß, A. Winkelmann, Detecting potential weaknesses in business processes: An exploration of semantic pattern matching in process models, Business Proc. Manag. Journal 21 (2015) $25-54$. 
[29] H. A. Reijers, S. L. Mansar, Best practices in business process redesign: an overview and qualitative evaluation of successful redesign heuristics, Omega 33 (2005) 283-306.

[30] A. Afuah, C. L. Tucci, Crowdsourcing as a solution to distant search, Academy of Management Review 37 (2012) 355-375.

[31] D. Berardi, D. Calvanese, G. De Giacomo, M. Lenzerini, M. Mecella, Automatic service composition based on behavioral descriptions, International Journal of Cooperative Information Systems 14 (2005) 333-376.

[32] M. L. Rosa, M. Dumas, A. H. M. ter Hofstede, J. Mendling, Configurable multi-perspective business process models, Inf. Syst. 36 (2011) 313-340.

[33] M. Zur Muehlen, Workflow-based process controlling: foundation, design, and application of workflow-driven process information systems, volume 6, Michael zur Muehlen, 2004.

[34] J. Claes, I. Vanderfeesten, F. Gailly, P. Grefen, G. Poels, The structured process modeling method (SPMM) what is the best way for me to construct a process model?, Decision Support Systems (2017).

[35] S. Suriadi, M. T. Wynn, J. Xu, W. M. van der Aalst, A. H. ter Hofstede, Discovering work prioritisation patterns from event logs, Decision Support Systems (2017).

[36] M. T. Wynn, E. Poppe, J. Xu, A. H. ter Hofstede, R. Brown, A. Pini, W. M. van der Aalst, Processprofiler3d: A visualisation framework for log-based process performance comparison, Decision Support Systems (2017).

[37] S. K. vanden Broucke, J. De Weerdt, Fodina: a robust and flexible heuristic process discovery technique, Decision Support Systems (2017).

[38] N. Martin, M. Swennen, B. Depaire, M. Jans, A. Caris, K. Vanhoof, Retrieving batch organisation of work insights from event logs, Decision Support Systems (2017).

[39] R. Mans, N. C. Russell, W. M. P. van der Aalst, P. J. M. Bakker, A. J. Moleman, Simulation to analyze the impact of a schedule-aware workflow management system, Simulation 86 (2010) 519-541. 
[40] G. Havur, C. Cabanillas, J. Mendling, A. Polleres, Resource allocation with dependencies in business process management systems, in: M. L. Rosa, P. Loos, O. Pastor (Eds.), Business Process Management Forum - BPM Forum 2016, Rio de Janeiro, Brazil, September 18-22, 2016, Proceedings, volume 260 of Lecture Notes in Business Information Processing, Springer, 2016, pp. 3-19.

[41] P. Hoenisch, D. Schuller, S. Schulte, C. Hochreiner, S. Dustdar, Optimization of complex elastic processes, IEEE Trans. Services Computing 9 (2016) 700-713.

[42] M. Hepp, F. Leymann, J. Domingue, A. Wahler, D. Fensel, Semantic business process management: A vision towards using semantic web services for business process management, in: F. C. M. Lau, H. Lei, X. Meng, M. Wang (Eds.), 2005 IEEE International Conference on e-Business Engineering (ICEBE 2005), 18-21 October 2005, Beijing, China, IEEE Computer Society, 2005, pp. 535-540.

[43] I. Weber, X. Xu, R. Riveret, G. Governatori, A. Ponomarev, J. Mendling, Untrusted business process monitoring and execution using blockchain, in: M. L. Rosa, P. Loos, O. Pastor (Eds.), Business Process Management - 14th International Conference, BPM 2016, Rio de Janeiro, Brazil, September 18-22, 2016. Proceedings, volume 9850 of Lecture Notes in Computer Science, Springer, 2016, pp. 329-347.

[44] S. Satyal, I. Weber, H. young Paik, C. D. Ciccio, J. Mendling, Ab-bpm: Performance-driven instance routing for business process improvement, in: A. Kumar, G. Engels, J. Carmona (Eds.), Business Process Management - 15th International Conference, 2017. Proceedings, Lecture Notes in Computer Science, Springer, 2017.

[45] M. Reichert, B. Weber, Enabling Flexibility in Process-Aware Information Systems, Springer-Verlag, 2012.

[46] J. Evermann, J.-R. Rehse, P. Fettke, Predicting process behaviour using deep learning, Decision Support Systems (2017).

[47] T. W. Malone, K. Crowston, J. Lee, B. Pentland, C. Dellarocas, G. Wyner, J. Quimby, C. S. Osborn, A. Bernstein, G. Herman, et al., 
Tools for inventing organizations: Toward a handbook of organizational processes, Management Science 45 (1999) 425-443.

[48] F. Thiesse, J. Al-Kassab, E. Fleisch, Understanding the value of integrated rfid systems: a case study from apparel retail, European Journal of Information Systems 18 (2009) 592-614.

[49] C. Di Ciccio, H. van der Aa, C. Cabanillas, J. Mendling, J. Prescher, Detecting flight trajectory anomalies and predicting diversions in freight transportation, Decision Support Systems 88 (2016) 1-17.

[50] J. I. Criado, R. Sandoval-Almazan, J. R. Gil-Garcia, Government innovation through social media, Government Information Quarterly 30 (2013) 319-326. 